Session 2632

\title{
LEADERSHIP EDUCATION AT THE UNIVERSITY OF MICHIGAN
}

\author{
ANDREW S. CRAWFORD \\ University of Michigan
}

\section{INTRODUCTION}

The College of Engineering is making "team building" an instructional commitment as part of the revision for our Curriculum 2000. Students will have curricular instruction in aspects of team building and the opportunity to practice these skills in significant team projects during each year of their education. Part of our goal is to meet the ABET requirement to demonstrate that our graduates have "an ability to function on multi-disciplinary teams."

The University of Michigan has developed a model for leadership based on developing "skills" that are applicable for different leadership or citizenship roles. Each student has differing goals and capabilities around mastering their "leadership" potential. The College of Engineering has established a minimum level of team skills required for each of our graduates. These involve skills in relating with team members, in accepting roles and responsibilities that contribute to the team, and in developing and implementing effective group decisions. We will assist students who choose to master skills in "team building" and "leadership" beyond the requirements to get the needed instruction and practice.

There is controversy about the ability of any university to develop "leaders"i. We recognize that many students will not choose to, or have the basic skills to, become classic hierarchical leaders. Our hope is that we can help all students to become effective members of teams and to rise to informal leadership roles when the situation demands. Research by Debra Moriartyii shows that students who participate in a leadership class or program coupled with co-curricular activities report the highest levels of leadership ability. We expect to be able to develop leadership ability through our programs. A significant challenge is to assess these programs over time to refine them to better meet our goals.

This paper begins with a description of the skill-based model developed by the Michigan Leadership Initiative task force. It defines "competency," "leadership" and "citizenship" from the perspective of how these concepts are applied in our program. The paper describes our conceptual model and shows the progression of skills to be obtained over the four years of undergraduate education. Plans for implementing the model in the College of Engineering are described. These were developed by a committee with members from each of the departments in the College. The freshman module, currently in place, provides an example of how the plan will be implemented. Finally, the challenges of assessing progress and implementing future stages of the plan are discussed. 


\section{THE MODEL FOR LEADERSHIP EDUCATION AT MICHIGAN A. MLI Organization and Task Force}

The importance of helping students become effective leaders and active citizens is demonstrated throughout the University of Michigan community. The University's mission statement explicitly references "developing leaders and citizens who will challenge the present and enrich the future". iii As is evident in the mission statement and throughout the work of the institution, the University values the importance not only of providing leadership and developing active and engaged citizens, but also of excelling as we strive to make our mark on the world.

The Michigan Leadership Initiative (MLI) is a University-wide group formed by the Executive Offices of the University in 1994. The purpose of MLI is to create a more intentional and integrated approach to leadership and citizenship education. In August 1996, the MLI Board of Directors adopted a vision statement for leadership education at the University and appointed a task force to begin the work of conceptualizing a comprehensive approach to leadership and citizenship education.

Sections B through G below are excerpted from the report of the MLI task force. ${ }^{\text {iv }}$

\section{B. Framing Leadership and Citizenship}

Leadership has as many definitions as it does manifestations. In 1985, Bennis \& Nanus cited over 300 definitions of leadership in their research. It is not surprising that this task force chose not to define leadership for students. Defining leadership is difficult, partially because of the paradigm shift away from traditional "command and control" models to those that are more inclusive, shared, and collaborative in naturev. We (i.e., the MLI task force) are now recognizing that leadership can and does occur at all levels of organizations and in all kinds of settings. Leadership is increasingly being recognized as an interactive process that takes place between members of an organization. It is not simply a skill employed by a person in a position of power within an organization. It is also more than becoming an expert in one's field.

We also struggled with defining what makes a "good citizen". We came to believe that we are not talking about a legal definition (i.e., being a citizen of the United States), patriotism, and simple law abidance. We are talking about engaging individuals as active members of their community - in this case, the University of Michigan and its sub-communities. In general, we are talking about individuals who consider the needs of others, engage in societal issues, exercise their rights, and live up to their responsibilities. We believe that citizenship is an inextricable part of leadership.

\section{Leadership as a Process ${ }^{v i}$}

We view leadership as a process directed toward assisting a group to accomplish a goal, vision, or common purpose. There are many contexts and situations in which leadership can be applied, each with its own set of assumptions, perspectives, skills, and goals. The context and 
situation of leadership can depend on factors such as: the characteristics of the leadership opportunity, personal leadership ability, personal choice, and group dynamics.

Leadership can be exercised by a member of a group; it need not be only enacted by a positional leader. For example, participation in community service, role-modeling, and leading by example are forms of leadership that are not necessarily positional.

\section{Citizenship as Engagement}

We view citizenship as active participation by members of a community. Students who are actively engaged in both classroom learning and in their larger community are participating in citizenship enhancing activities. Some of the concepts that we think need to be examined and explored in a model of citizenship education include:

- developing an awareness and knowledge of public and societal issues

- actively participating in the community (or multiple communities) in a way that contributes to its operation and functioning

- taking responsibility for one's personal actions and their impact on other people and groups

- expanding the connections between one's classroom learning and one's experiences in the wider university and community

- infusing civic-mindedness into paid and unpaid work and professional careers

- understanding the connections between one's immediate efforts and larger societal interests

- actively seeking out new experiences

- valuing the importance of civility by learning productive ways to disagree.

We believe that by exposing our students to activities that will encourage and enhance their civic-mindedness, the results will include not only stronger communities at the University but also students who build habits that will have lasting impact and numerous applications after graduation. Students who are actively engaged in their university education will be in a better place to develop, or at the very least be exposed to, a broader range of life-enhancing skills.

\section{E. The Outcomes}

There are numerous outcomes of the leadership process and citizenship engagement, some distinct and many interrelated. Leadership and citizenship may result in tangible outcomes such as the achievement of a particular objective, realization of vision, or noticeable qualitative change. The process of engagement may also elicit empowerment, subtle influence, heightened awareness, and skill strengthening or development in both individuals and groups.

\section{F. The Skills and Characteristics of Effective Leaders and Active Citizens}

To be both an effective leader and an active citizen, one needs to master a variety of skills and acquire a specific set of knowledge. A significant part of the developmental process for emerging leaders has to be to identify the skills and knowledge they need to be effective in their 
chosen field and in the various types of situations they will encounter. These skills and knowledge fit within a number of broad categories (see Appendix A for detailed lists):

- Knowledge and Thinking Skills

- Personal Skills

- Relationship Skills

- Group Facilitation Skills

- Goal Management Skills

- Visioning Skills

- Political Skills

- Social Responsibility Skills \& Ethics

\section{G. The Model for Education}

The model for leadership and citizenship education utilizes five processes with which students can evaluate and purposefully develop their personal skills and abilities. This model asserts that the most effective education and development occurs when all five processes are continuously employed. This is the most general form of the model. The following are the five processes involved in the model for leadership and citizenship education.

Self-Assessment: Individuals need to be able to identify and assess their personal skills and abilities. They need to be encouraged to continuously evaluate their strengths and weaknesses. Additionally, students should be encouraged to solicit and be open to others' feedback so that they may better identify their strengths and weaknesses.

Situational Needs Evaluation: Students need to be able to identify and understand the skills and knowledge that a specific developmental opportunity or experience requires of them as well as those that will be most effective. This can be facilitated through discussion and feedback with another such as a professor, advisor, or peer and/or be self-driven.

Self-Situation Skill Match: Students need to be able to assess how their personal skills and abilities match with the skills required by a specific or selected opportunity or experience. This can be facilitated by another such as a professor, advisor, or peer and/or be self-driven.

Skill Acquisition: When students become aware of the personal skills that they need to develop or enhance, they need to have opportunities and encouragement to acquire them. Optimally these opportunities should incorporate and compliment both the classroom and co-curricular environments. These opportunities need to challenge students' personal abilities so that they may develop skills that they do not possess and refine those that they do.

Reflection: Students need to be able to reflect on their experiences to create meaning and better understand themselves. Students should be encouraged to reflect on their skills, abilities, tendencies, 
as well as their growth as they purposefully develop new skills. Classroom and co-curricular opportunities and encouragement for students to engage in dialogue about the concept of leadership and citizenship will enhance and motivate students' reflection.

\section{DEFINITIONS AND BASIC CONCEPTS}

As we have developed the model and begun the implementation process, we have found that it is very important to continually clarify terms. Our community has a wide variety of interpretations for the words "leadership" and "skills".

Because "leadership" is so often identified as a positional role occupied by relatively few individuals, we often find it preferable to substitute "team skills" or "interpersonal skills" when discussing specific leadership-related programs or activities. Following the MLI model of leadership as a process, students must develop interpersonal skills, use them to master team participation skills before they can move on to collaborative or hierarchically- based leadership skills.

We find similar problems with the term "skills" and are moving towards the industry concept of "competency". According to Lyle Spencervii, a competency is an underlying characteristic of an individual that is causally related to criterion-referenced effective and/or superior performance in a job or situation. Underlying characteristic means the competency is a fairly deep and enduring part of a person's personality and can predict behavior in a wide variety of situations and job tasks. Causally- related means that a competency causes or predicts behavior and performance.

Spencer describes five competency characteristics:

Motives: the things a person consistently thinks about or wants that causes action. Traits: physical characteristics and consistent responses to situations or information. Self-Concept: a person's attitudes, values, or self-image.

Knowledge: information a person has in specific content areas. $\underline{\text { Skill: }}$ the ability to perform certain physical or mental tasks. 


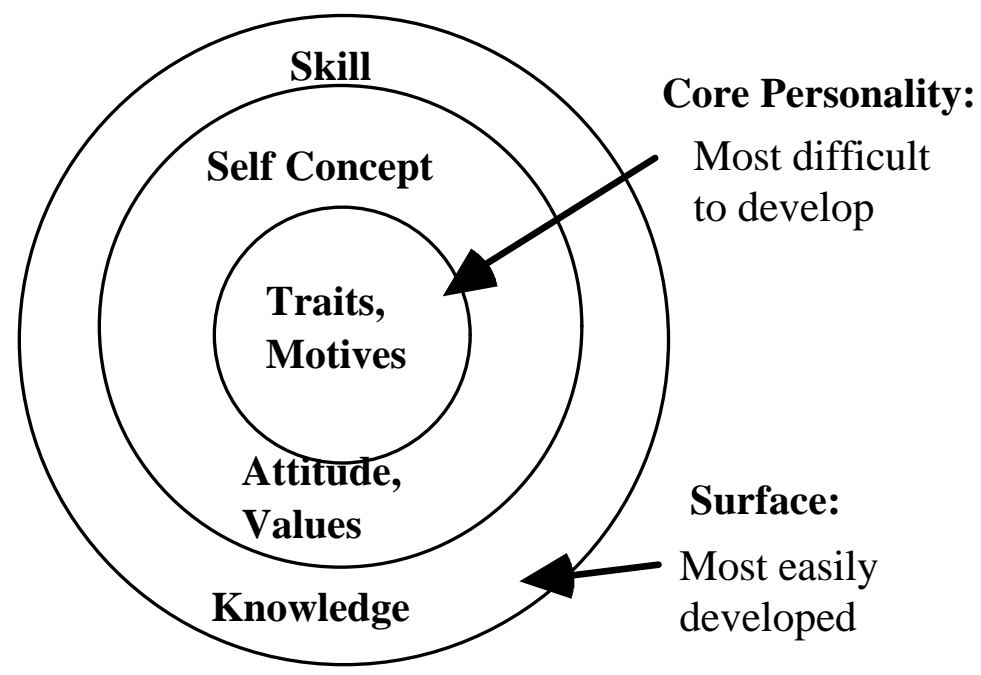

A class or semester program can assist a student to develop knowledge and skills. A more comprehensive program over the full undergraduate program can develop attitudes, values and a self concept directed towards leadership. The values and examples of the institution and the members of the faculty can assist to develop the motive of leadership.

The Covey viii concept of habits as being the intersection of knowledge, skills and desire parallels the model for developing competencies. The classroom is very effective in teaching knowledge, but less effective in developing skills and desire. Internships and co-curricular activities become a way to build knowledge into skills.

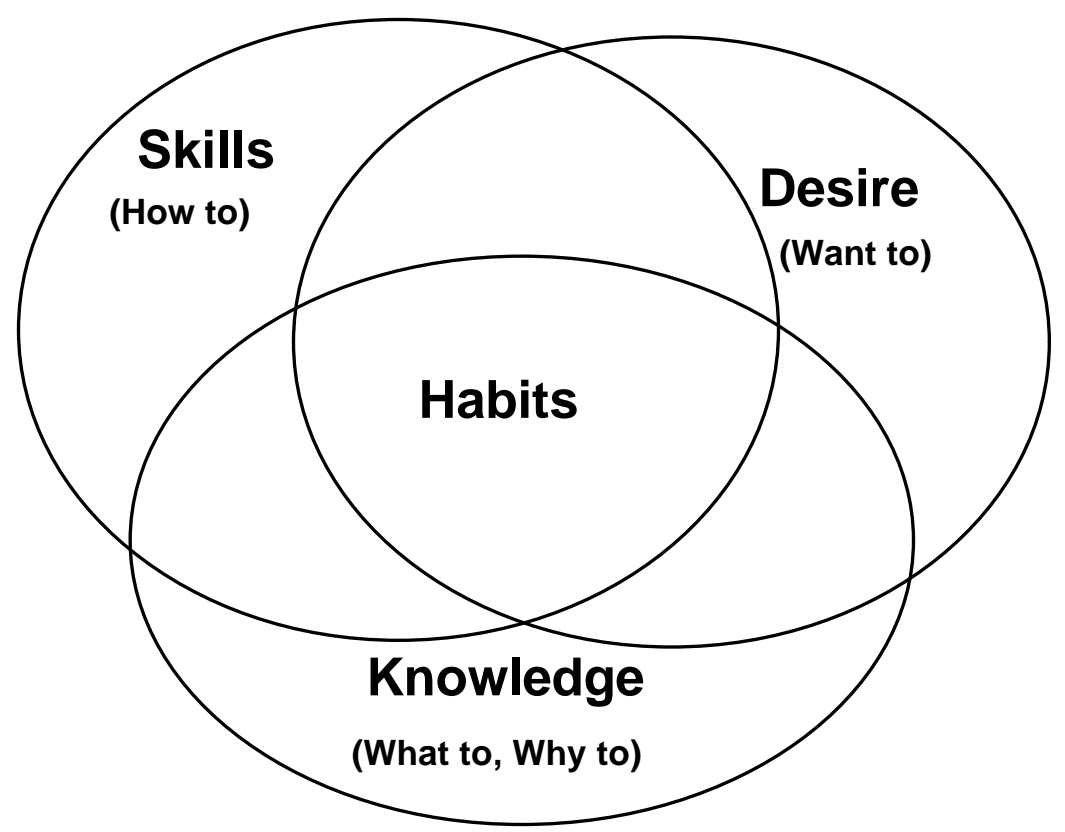

Students have a wide range of goals and motives relative to their choice of majors, specific courses and additional activities. Their interest in developing interpersonal and leadership 
competencies is influenced by their specific career goals and their individual character tendencies, and also by the values of their institution. A graduate's career is influenced both by professional competencies and interpersonal competencies. Institutions, such as the College of Engineering, have been very specific in defining a minimum level of technical competencies for graduates but have avoided requiring (much less teaching) interpersonal competencies.

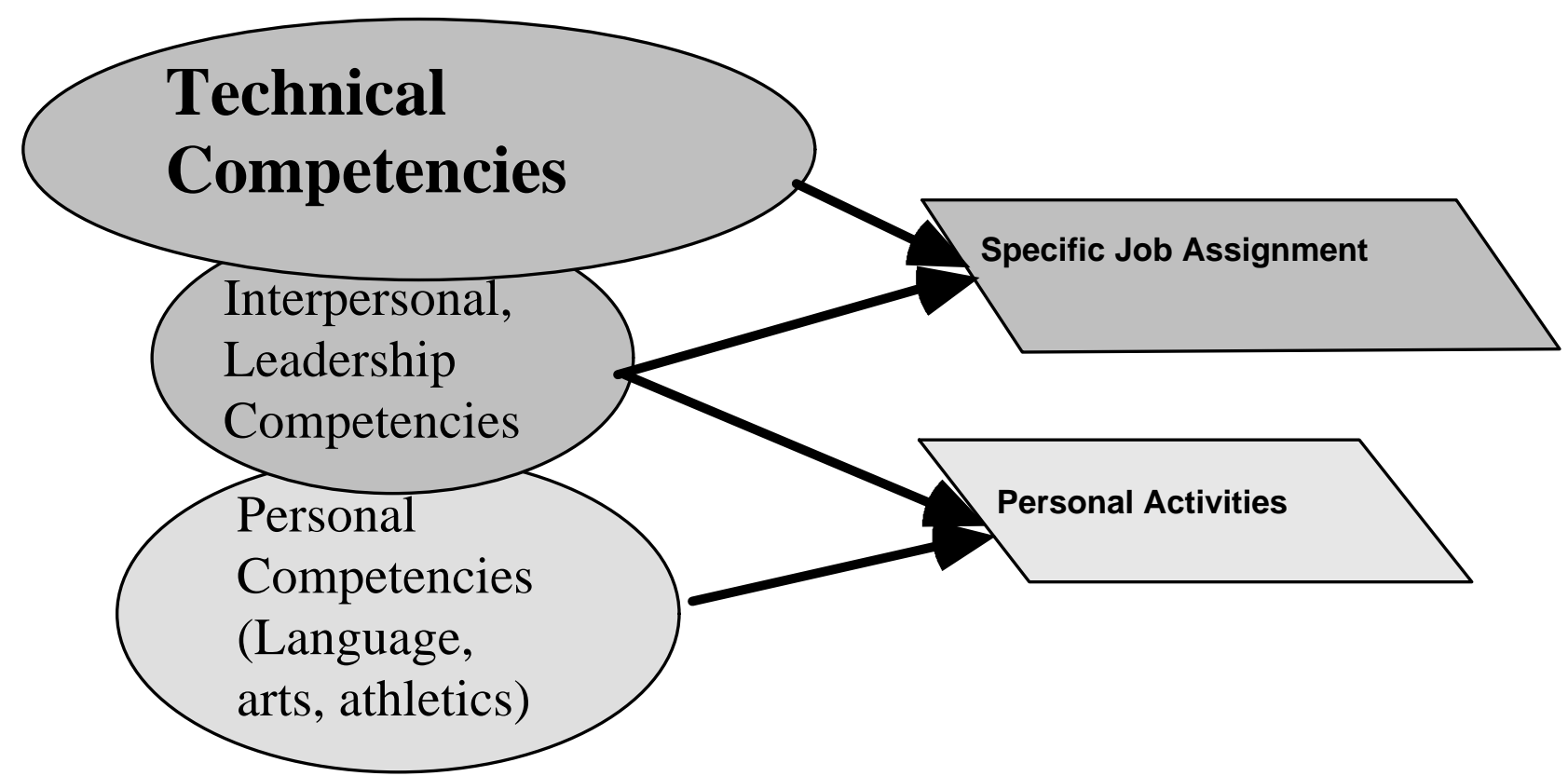

\section{COLLEGE OF ENGINEERING COMMITMENT TO TEAM SKILLSix}

The College of Engineering is committed to implementing the mission of the University to create "leaders and citizens who will challenge the present and enrich the future." Team skills are integral to leadership and there is a strong movement in the College to include the ability to work in groups or teams as a fundamental skill for all engineers. As proposed by Curriculum 2000, "leadership and team building/working skills and experiences" is one of the knowledge sets ("threads") that will characterize the Michigan engineering B.S. and B.S.E. degrees. Team skill development is further motivated by the ABET Engineering Criteria 2000 requirements which state that engineering programs must demonstrate that their graduates have "an ability to function on multi-disciplinary teams."

Michigan engineering graduates will work in a variety of professional contexts in which they will learn that both individual and team competencies are important, and that the nature of the task determines whether it is more effective and efficient to work individually or as a team. Teams can bring a greater degree of knowledge and expertise and can accomplish certain tasks or projects in a shorter amount of time and at less cost if the members have developed certain skills.

In March 1997, a committee was charged by the Associate Dean for Undergraduate Education to propose an engineering curriculum model for team skill development. This committee was chaired by the author who served as a member of the Undergraduate Curriculum Task Force and is currently serving as the team building content specialist in the new Engineering 100 course, 
Introduction to Engineering (Appendix $C$ ). The following themes guided the committee's work in developing the recommendations contained in their report:

1. Team project work is an integral part of engineering education.

2. Team skill development progression from the freshman to senior level courses will be reinforced through formal instruction and active learning opportunities.

3. Materials for teaching team building will be designed to make it easy for faculty to incorporate team building tools into their courses.

4. Graduates will be able to work effectively in groups on multi-disciplinary design problems.

Currently, most of our degree programs have senior design courses which are intended to provide students with significant practical opportunities to apply knowledge and skills in a teambased environment. We recognize that some engineering lab courses are also project-team oriented. While these experiences can provide students with valuable opportunities to work with others in solving engineering-related problems, learning is sometimes minimized as a result of team process problems. These problems may not only cause a project to fail but may also create significant interpersonal conflicts among team members. Faculty report that most team efforts are productive and successful but it takes a considerable amount of additional time and effort on their part to work with teams which are dysfunctional.

\section{A. Team Building Concepts for Core Courses}

Selected courses will be identified to include focused instruction on team building skill development. In Engineering 100, students will be introduced to and tested on the following topics:

- establishing group norms and roles

- procedures for effective meetings

- establishing group goals

- dealing with conflict

- evaluating performance

- providing feedback to team members

- taking personal responsibility for actions

- effective communication

- team building procedures

- creating detailed action plans.

Students will practice these skills in a structured environment with considerable supervision and support.

In at least one sophomore course taught by each department, instructors will be encouraged to utilize a standard set of instructional material. This set will include information on three core concepts: problem solving model; basic elements of team building; and management of self. The College will provide detailed instructional materials, course pack materials, and exam questions to support these concepts. It is important to teach these in a team-based course where students have an opportunity to practice the skills in a supervised environment. 
In at least one junior course taught by each department, instructional material will include information/guidelines on project management, setting of stretch (risky) goals, and division of labor. Again, this is most appropriately taught in a team-based course where students have an opportunity to practice the skills.

Instructional materials are intended to provide a framework to support teaching of team skills with clearly-stated learning outcomes at each level. The goal is to provide continuity across the curriculum where students will be encouraged to develop and strengthen team skills as they advance in their academic fields. Instructors will have access to sample assignments that fit within normal course expectations and reinforce previous team experiences. Materials will be readily available both in printed and electronic (WWW) form.

\section{B. Instructional Model for Implementation in the Fall Term 1998}

\section{Sophomore Course: Introduction to Department}

Core Concepts

Team Activities

Projects
Problem solving model

Basics of team building

Management of self

Structured project

Narrow skill differences on team

Specified format of meetings

Collaborative and fun

Some instructor specifications

Range of possible problems and solutions

Low risk

Specific Instruction Covey, S. Seven Habits of Highly Effective People. (New York: Simon \& Schuster,1989).

Problem solving model

Stages of group development

Exam content

\section{Seven Habits of Highly Effective People \\ Problem solving model \\ Stages of group development}

A typical course at the sophomore level would utilize teams as a way to get students working on more complex problems that develop a broad understanding of the new material. Thus a design project with greater complexity could be divided into pieces that are each done by an individual but also coordinated by the team. A research project could cover a much greater range of issues. In general, these projects would be specified by the instructor, have a range of possible problems and solutions, and be solvable by high functioning teams. 
For courses intended to meet ABET team training requirements, departments would be expected to teach material on the three core concepts mentioned previously: problem solving model; basic elements of team building; and management of self. Each of these concepts would require 1.52.0 hours of instruction as well as one out-of-class assignment and one quiz or exam question.

The following standard team operating procedure should be closely adhered to in all sophomore level team-oriented courses:

1. A "forming" exercise where team members get to know each other in a formal procedure.

2. A "storming" exercise where the team agrees on team goals and rules. These would be submitted to the instructor and reviewed twice.

3. A standard meeting procedure which includes appointing a facilitator and recorder, and utilizing agendas and minutes (to be reviewed by instructor).

4. A written set of project goals and a formal plan of action.

5. An assessment of team performance midway through the project and at the end of the project (to be reviewed by instructor).

These required operating procedures will be introduced in Engineering 100 and standard materials will be available for faculty to utilize in their syllabi and course packs.

\section{Junior Course: Significant Design Problem}

Core Concepts

Team Activities

Projects

Specific Instruction
Project management

Setting stretch goals (risk taking)

Division of labor

Negotiating

Low structure

Moderate skill differences

Encourage team leader

Division of labor required

Project should require hard work

Open-ended problems

Medium risk about outcome

High grading standards

Creating a plan based on goals

Setting stretch goals (risk taking)

Creating a schedule from plan

Management tools

Negotiating

A typical course at the junior level would use teams as a way to increase the complexity, risk and level of effort on projects. These projects would have low levels of structure, depend on 
different skills among team members, and require a division of labor. These projects should entail considerable team effort, allow some risk of failure by teams and have high grading standards.

Students will be expected to increase their level of knowledge in project management skills at this point in their education. Some departments may choose to require a project management course. It is recommended that the College provide a standard set of project management materials for use in a course or to be used independently by students who are interested in strengthening their skills.

Teams will be expected to follow the standard team operating procedures outlined for the sophomore year. In the junior year, instructors may choose to be less involved in reviewing team norms and meeting records.

\section{Senior Course: Professional Design Problem}

Core Concepts

Team Activities
Projects require vision

Projects require innovation

Very open structure

Multi-disciplinary skills

Division of work on team

Encourage a team leader

Hard work required to achieve success

\section{Projects}

Focus on innovation

Stretch goals

Professional grading standards

As mentioned earlier, the proposed ABET Engineering Criteria 2000 require that engineering graduates be able to function effectively on multi-disciplinary teams. Students are likely to participate on multi-disciplinary design teams as part of their senior design course. These teams will be expected to create a design and/or solve a complex problem by drawing on individual skills with the expectation that the team experience will achieve a better result than any one person. This will be accomplished with less total effort than would be expended by a single individual for a similar outcome.

Senior level design projects will require that students address an open-ended problem requiring vision and innovation. Work on the project will be divided among members who bring different skills, generally coordinated by a designated team leader. There should be significant risk of failure and the project should be graded based on real world professional standards.

Teams will be expected to follow the standard team operating procedures outlined for the sophomore year. In the senior year, instructors may choose to be less involved in reviewing team norms, goals, meeting records and assessments.

\section{Model For Team Performance}




\section{Developmental Skills-Based Model}

Teams progress through a series of developmental stages before optimum team performance can be achieved. Team members can accelerate this process by recognizing the different stages of team development and systematically applying their knowledge, skills and abilities at each stage as they collectively advance towards a common goal. Students will become familiar with the stages of team development in Engineering 100. Through a reflection and assessment process at the end of each team experience, students can incorporate what is learned and apply this knowledge to their next team project. Success in this process can provide students with an enhanced appreciation for the value of teamwork and a greater sense of accomplishment and satisfaction. The four stages of team development named, and based on the work of Tuckman and Jensen (1977), are:

\begin{tabular}{l}
\hline Stage I: "FORMING" \\
\hline - get acquainted with members and project \\
- develop a level of trust \\
Stage II: "STORMING" \\
- identify strengths and growth areas \\
- develop behavioral ground rules \\
- clarify project and specific tasks \\
- determine performance standards \\
Stage III: “NORMING" \\
- identify necessary skills for each task \\
- utilize strengths and nurture interests \\
- identify decision-making procedures \\
- assign tasks \\
Stage IV: "PERFORMING" \\
- complete tasks \\
- ongoing internal assessment
\end{tabular}

"It is estimated that $50 \%$ of an engineer's work is associated with relationships. It is the overlap between task productivity and relationship morale that results in effective team output. Thus a team's effectiveness can be measured by its ability to achieve its objectives and satisfy the needs of individual team members at the same time."x. Ideally, graduating seniors should be able to accept a team assignment, build a positive and professional working relationship with fellow team members, and contribute in a meaningful way to the overall team effort. They should be able to do so whether the task requires an hour, a few days or many months to complete. The tables found in Appendix $D$ identify the competency areas and the specific skills associated with each area. It also identifies the year in which the skill should first be introduced through formal instruction and active learning opportunities. These skills will continue to be developed but will likely require little or no formal instruction. 


\section{CURRENT WORK ON DEVELOPING MODULES}

A team of faculty and students are organizing materials for each of the individual "skills" with the goal of having a package of instructional material that would be easy to use by an individual faculty member, a WEB-based set of material that would encourage self instruction, and a set of outside reference materials to support each of these. The basic engineering skill modules should be completed during the summer of 1998.

The instructional materials will include a basic student self-assessment module, course pack materials that cover the basic concepts of each skill, class and individual exercises that support the readings, lecture outlines and slides, and exam questions. The WEB-based materials will be targeted to students who are not able to take courses that include these materials. The WEB materials will be coordinated by Michigan Leadership Initiative with the expectation of eventually reaching most, if not all, undergraduate students. The proposed model under development follows these stages:

Goal setting module for students. We have to help students collect enough data about their own values, interests, skills and opportunities to set some career and life goals. We see this as a progressive process where they start by narrowing down the field and exploring the desirability of the choice and their level of ability. As they have more knowledge they get deeper into the decision. Speakers, reading materials, internships will all be aids to assist in this process.

Competency map associated with a set of career and life choices. As a student sets goals, a target set of competencies is developed. These will tend to be serial threads of different types of competencies . At the start of the threads, the competencies will be similar and basic for many students. As the students progress, there will be branch points and gateways.

Competency testing. Students will undergo a series of tests to evaluate current competencies against their target. Sometime, especially at the start of a program, these tests will be basic and low on content. As the student progresses, these tests will help accomplish a form of accreditation.

Learning opportunities. The comparison between the desired competency map and the current set of competencies identifies learning opportunities. In general these are ordered by the nature of the thread (e.g., you learn to facilitate meetings before you master building a team). For the current high priority opportunities the student will be offered a variety of options on how to develop the skills. These may be curricular, self learning, internships or research, and co-curricular.

Education plan. Based on the student's time, course availability and personal preferences, the student will choose a set of goals and make a plan for the following period. This will become the focus of the student's attention for the next semester (or year.)

Reflection. At the end of the study period, the students will go through a round of competency testing and assessment, reflect on their progress and their goals. This becomes the point at which they start the process over again. 


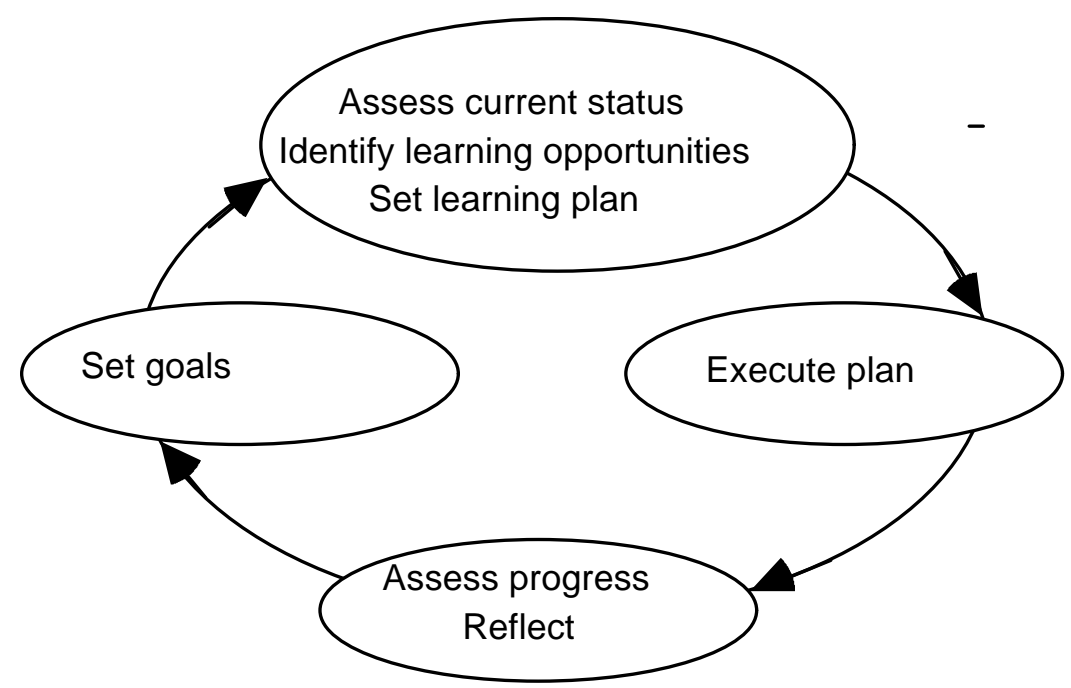

The Kellogg Foundation has provided funding for the development of curricular materials in leadership and citizenship that will be used to further develop and test modules. An attempt is underway to develop partnerships with commercial firms to utilize modules that they have for teaching and assessing these skills.

\section{A. Assessment of Progress}

We recognize the need to assess our progress on this project and our desire to do it effectively. Work is underway with assessment experts in the Office of Students Affairs and Center on Research on Learning and Teaching (CRLT) to establish clear hypotheses for testing and methodologies for gathering and evaluating data.

\section{Appendix A}

The following is the list of skills included in the model for leadership and citizenship education. It is likely that there are more skills associated with the development of leadership and citizenship which can be added as identified.

\section{Knowledge and Thinking Skills}

- ability to analyze and synthesize information

- critical thinking skills

- content knowledge in specific fields

\section{Personal Skills}

- active listening

- cultural awareness and understanding

- communication skills (verbal, written, interpersonal)

- time management

- accountability

- self-awareness 
- $\quad$ stress management

- risk-taking

- flexibility

\section{Relationship Skills}

- giving and receiving feedback

- trust-building

- assertiveness

- recognizing and utilizing other people's strengths and weaknesses

- mentoring skills

- conflict resolution

- valuing diversity

\section{Group Facilitation Skills}

- team-building

- facilitating productive meetings

- gatekeeping

- consensus-building

- action planning

- taking on new roles within a group

- conflict management

- understanding stages of group development

\section{Visioning Skills}

- ability to assess and articulate the status quo

- needs assessment

- ability to create and articulate a vision

- enlistment - building support

- empowerment

\section{Goal Management Skills}

- identifying and defining a problem

- developing solutions

- goal setting

- project planning

- plan execution

- negotiation skills

- group decision-making

- developing leadership skills in team members

- delegation skills

- networking skills

\section{Political Skills}

- understanding organizational culture

- understanding the decision-making process and its consequences

- coalition-building 
- compromise

- change management skills

\section{Social Responsibility Skills \& Ethics}

- personal values

- integrity

- ability to view ideas from different perspectives

- ethical decision-making 


\section{Appendix B}

\section{EXAMPLES OF GROUP FACILITATION SKILLS ${ }^{x i}$}

The following outline provides a detailed description of Group Facilitation Skills (referenced in Appendix A). This outline can be used as the basis for organizing materials and teaching these skills.

Facilitating productive meetings [Freshman Year]

Purpose: Meetings can be effective ways of communicating information and reaching decisions.

Techniques: When you are facilitating a meeting:

- Use an agenda to focus the discussion.

- Allot time periods for discussion of each item.

- Establish roles within the group for the meeting, such as scribe, timekeeper.

- Model roles you would like to see other members take on.

- Actively participate in the discussion.

- Summarize the meeting so that everyone knows what has been decided.

- End the discussion with an action plan for the group as well the responsibilities of individual attendees.

- Evaluate how well the group functioned and seek ways of improving the effectiveness of the meeting.

- Express your appreciation for the group's time and contributions to the meeting.

Learning Outcomes: By facilitating a productive meeting, you can learn how to:

- design an agenda that fits the time allocated.

- ensure that members feel comfortable offering their ideas and opinions.

- involve everyone in the group process.

\section{Outcome Assessment:}

Exam on basic issues involved with facilitation.

Experience facilitating a series of meetings with a project team, with member assessment. Paper and interview with a GSI or instructor about experience in doing facilitation.

\section{References:}

http://www.mindtools.com/tmmeetng.html

Johnson, D.W., \& Johnson, R. Positive Interdependence: The heart of cooperative learning. Edina, MA: Interaction Book Company, 1992.

Johnson \& Johnson. Joining Together. Needham Heights, MA: Allyn \& Bacon, 1997, pp. 481483.

Gatekeeping [Freshman Year] 
Definition: Ability to bring all members into the process.

Purpose: Gatekeeping allows all members of a group to be heard and prevents important information or ideas from being lost.

\section{Techniques:}

- Bring members of the group into the conversation.

- Facilitate procedures or group activities.

- Create a climate of comfort and open communication.

Learning Outcomes: Gatekeeping results in:

- greater participation by all members.

- free expression of differences of opinions.

\section{Outcome Assessment:}

An eight meeting experience where there is a focus on involving other members in specific ways.

An assessment by those members of their perception of the gatekeepers skill.

Paper and interview with a GSI or instructor about experience in doing gatekeeping

\section{References:}

Benne and Sheats, "Functional Roles of Group Members," Journal of Social Issues 4 (Spring 1948), pp. 41-49.

Leadershape ${ }^{\circledR}$ Manual, Day\#3 - p. 59.

Consensus building [Freshman Year]

Definition: "Consensus is arrived at by a group of individuals working together under conditions that permit communication to be sufficiently open - and the group climate to be sufficiently supportive - for everyone in the group to feel that he or she has had a fair chance to influence the decision." *

Purpose: Consensus is a good way to generate a creative and high-quality decision and fosters sustained and effective group decision-making.

Techniques: Consensus requires members of a group to:

- formulate and articulate opinions.

- listen to the opinions and feelings of the other members.

- consider the alternative perspectives with genuine interest.

- remain flexible when reaching a group decision.

Learning Outcomes: Consensus building leads to:

- acceptance of different positions and perspectives.

- a sense of ownership in the decision or solution by members of the group.

- innovative and high-quality decisions which incorporate the strengths and expertise of all members. 
Outcome Assessment: A set of exercises where the individual focuses on summarizing and consensus building with an ongoing team. Ask for evaluation by the members of the team at the end of the exercise.

References:

*Johnson \& Johnson, Joining Together. Needham Heights, MA: Allyn \& Bacon,1997, pp. 250-1. Leadershape® Manual, Day \#3 - p. 61

\section{Understanding stages of group development [Freshman Year]}

Definition and Purpose: To recognize and understand the group development process which influences members' behaviors as well the issues groups must address.

Techniques: :Recognize and observe the different developmental stages of groups:

- Forming - members become acquainted, learn about and accept each other.

- Storming - members challenge each other on opposing thoughts and opinions.

- Norming - group develops a set of norms and builds a sense of community.

- Performing - group works as a team to accomplish group goals.

- Adjourning - group discontinues working together.

Learning Outcomes: By becoming aware of the group development process, groups can understand the theory behind the various stages and positively effect team cohesion and productivity.

Outcome Assessments: Exam on the theory and basic information about group development.

References:

Johnson \& Johnson. Joining Together. Needham Heights, MA: Allyn \& Bacon, 1997, p. 23. Tuckman \& Jensen. "Stages of small group development revisited". Group and Organization Studies, 2, 1977, pp. 419-427.

Conflict management [Freshman Year]

Purpose: For controversies to be managed constructively, people need collaborative and conflict management skills.

Techniques:

- Separate the person from the conflict, by disagreeing with the idea or thought while simultaneously confirming the other's personal competence.

- Show genuine interest in listening to the other person's ideas.

- Take a neutral perspective to facilitate communication and understanding.

- Seek out information for clarification.

- Integrate ideas to reach an agreement.

Learning Outcomes: Conflict management results in: 
- a situation satisfactory and beneficial to all those involved.

- an agreement that capitalizes on everyone's strengths and interests.

- a greater willingness to incorporate others' information/reasoning.

\section{Outcome Assessment:}

Exam on concepts of controversy and conflict, steps for conflict resolution, and goals of successful conflict management.

Feedback from team members on a semester long course on students ability to engage in controversy and resolve conflict.

\section{References:}

Bormann, Ernest and Nancy. Effective Small Group Communication. Minneapolis: Burgess Publishing Company, 1976.

Johnson \& Johnson. Joining Together. Needham Heights, MA: Allyn \& Bacon, 1997, pp. 313, 336.

Team building [Sophomore year]

Purpose: Efforts to develop a sense of teamwork are critical to improving "the effectiveness of ongoing work teams". *

\section{Techniques:}

- Create a group identity together and identify team goals.

- Build a desire for a group achievement of these goals.

- Develop an understanding of the group process.

- Build on group and individual strengths and acknowledge and assist with group or individual weaknesses.

- Work toward more cooperation and collaboration among members.

- Incorporate effective feedback.

- Celebrate successes and learn from failures.

Learning Outcomes: Team building emphasizes the analysis of group procedures and activities and leads to:

- improved team productivity.

- stronger or better quality relationships among members.

- increased level of social skills.

- ability to adapt to changing conditions and demands.

- increased long-term effectiveness.

\section{Outcome Assessments:}

Exam that tests knowledge of the stages, techniques to use at each stage, problems that arise when stages are not complete.

Evaluation of team members on an ongoing group on individuals skills in building their team.

Paper on experience in developing a team, reviewed by a GSI or Instructor. 
References:

Argyris, C. Integrating the individual and the organization. New York: Wiley, 1964.

Beckhard, R. Organizational Development. Reading, MA: Addison-Wesley, 1969.

Beer, M. Organization change and development: A systems view. Glenview, IL: Scott, Foresman, 1980.

Buller, P., \& Bell, C. "Effects of team building and goal setting on productivity: A field experiment. Academy of Management Journal, 29, 1986, pp. 305-328.

Dyer, W. . Team building: Issues and Alternatives. Reading, MA: Addison-Wesley, 1987.

* Johnson \& Johnson. Joining Together. Needham Heights, MA: Allyn \& Bacon, 1997, p. 526.

Taking on new roles within a group [Sophomore year]

Definition and Purpose: "Roles may be defined as a set of expectations defining the appropriate behavior of a position. Roles ensure that the... behaviors of group members are appropriately interrelated so that the group's goals are achieved." *

\section{Techniques:}

- Identify the different roles each member plays within the group.

- Recognize how an individual's strengths and weaknesses relate to their group role(s).

- Seek out ways to develop these areas for growth by experimenting in new roles.

Learning Outcomes: By expanding roles within the group, members may:

- step out of their comfort zones and try new and challenging team roles.

- understand and expand the roles an individual plays in contributing to team effectiveness.

- recognize the different roles an individual may need to assume at times within the group.

\section{Outcome Assessment:}

Establish a plan for a semester long team of roles that will be new and mastered.

Get assessment of the team members of success on developing the new roles.

Short paper on the process of trying new roles reviewed by GSI or instructor.

\section{References:}

Johnson \& Allen. "Deviation from organizational norms concerning the relations between status and power". Sociological Quarterly, 13, 1972, pp. 174-182.

* Johnson \& Johnson. Joining Together. Needham Heights, MA: Allyn \& Bacon, 1997, p. 20.

Milgram, S. Obedience to Authority. New York: Harper \& Row, 1974.

\section{Action planning [Sophomore Year]}

Definition and Purpose: "An action plan is a brief list of tasks that you have to carry out in order to reach an objective. It differs from a To Do list in that it focuses on the achievement of a (specific) goal." * 


\section{Techniques:}

- Assign individuals to complete the given task(s).

- Encourage members to work collaboratively in accomplishing these tasks.

- Keep in mind the end result or goal while performing the task(s).

Learning Outcomes: Drawing up an action plan allows you to:

- concentrate on the stages toward achieving your goal.

- monitor your progress towards that achievement.

\section{Outcome Assessment:}

Exam on the basic concepts of action planning, tasks and schedules.

Take on the role of making a plan for a semester long project team, get assessments of the team members at the end of the project.

Write a short paper on the experience for review by GSI or Instructor.

References:

* http://www.mindtools.com/actplan.html

\section{$\underline{\text { Appendix C }}$}

\section{ENGINEERING 100: INTRODUCTION TO ENGINEERING}

Engineering 100 is a new, required first-year course that provides an introduction to engineering problem solving, communications, ethics and team building. The students work with an engineering faculty member on a real problem. Their task is to develop a detailed solution as a team. Engineering 100 is a four credit hour course of which about $15 \%$ of the time is spent on instruction in team building. The following outline details major team building aspects of the course.

\section{Objectives of the team building aspects:}

(1) Create a belief in the value and importance of team work in the engineering profession.

(2) Create an understanding of the importance of good procedures to achieve teams that are effective, efficient, and fun.

(3) Create a commitment to develop the personal skills needed to be an effective member of a team.

(4) Teach the basics of effective meetings.

(5) Create a willingness to give and receive feedback.

(6) Provide a general introduction to setting goals, project planning, problem solving models, decision tools, and team building procedures.

\section{Nature of the team activities and procedures:}

(1) Highly structured project where the problem is well defined.

(2) Require group and meeting procedures, monitored by staff.

(3) Purely collaborative activities that are fun.

(4) Primary goal is to teach the benefit of good team behaviors.

(5) No significant skill difference between members. (Low skill members will be encouraged to attempt tasks with guidance of high skill members as part of the learning process.) 
Major instructional material (to be graded in exams):

(1) Meeting procedures

(2) Personal performance and roles in meetings

(3) Setting group goals and norms

(4) Giving and receiving feedback and assessment

(5) Conflict resolution

Secondary instructional materials (not to be graded):

(1) Standard problem solving model

(2) Stages of team building

(3) Decision making tools

(4) Importance of diversity, how to encourage diversity

Team assignments:

(1) Inter-personal communications and skill identification (Forming)

(2) Practice with group roles exercise (Forming)

(3) Team norm (rules) development (Storming)

(4) Group and individual goal development (Storming)

(5) Meeting structure requirements (Norming)

(6) Project goals, project plan (Norming)

(7) Feedback and assessment (Performing)

\section{$\underline{\text { Appendix D }}$}

First Year Sophomore Junior Senior

Core

Concepts

Role of individual on team

Importance of team work for engineers

Meeting management Management of self and participation

Elements of feedback

Team

Activities

Highly structured
projects
Required format for
stages and
meetings

Structured project

Narrow skill

differences on team

Specified format of

Collaborative and fun

meetings

Collaborative and

fun

Management of projects

Setting stretch goals (risk taking)

Division of labor

Negotiating

Low structure
Moderate skill
differences
Encourage team leader
Division of labor
required
Project should require
hard work

Very open structure Multi-disciplinary skills

Division of work on team

Encourage a team leader

Hard work to accomplish success

Open ended problems

Medium risk about
Focus on innovation

Stretch goals 


\begin{tabular}{|c|c|c|}
\hline $\begin{array}{l}\text { Close contact and } \\
\text { monitoring by } \\
\text { Instructor }\end{array}$ & $\begin{array}{l}\text { Range of possible } \\
\text { problems and } \\
\text { solutions }\end{array}$ & $\begin{array}{l}\text { outcome } \\
\text { High grading } \\
\text { standards }\end{array}$ \\
\hline $\begin{array}{l}\text { Problems reasonably } \\
\text { established } \\
\text { Focus on learning } \\
\text { about teams }\end{array}$ & Low risk & \\
\hline $\begin{array}{l}\text { Meeting procedures } \\
\text { Personal } \\
\quad \text { responsibility } \\
\text { Setting group norms } \\
\text { Setting group goals } \\
\text { Evaluation and } \\
\quad \text { feedback }\end{array}$ & $\begin{array}{l}7 \text { Habits of Highly } \\
\text { Effective } \\
\text { Individuals } \\
\text { Problem Solving } \\
\text { Model } \\
\text { Stages of group } \\
\text { development }\end{array}$ & $\begin{array}{l}\text { Creating a plan based } \\
\text { on goals } \\
\text { Setting stretch goals } \\
\text { (risk) } \\
\text { Creating a schedule } \\
\text { from plan } \\
\text { Management tools } \\
\text { Negotiating }\end{array}$ \\
\hline
\end{tabular}

Professional grading standards

\section{Specific Instruction}

Team Skills Meeting procedures on Exams

Six Habits of Effective Teams

Evaluation and feedback
7 Habits of Highly

Effective Individuals

Problem Solving Model

Stages of group development 


\section{Notes}

i Pascarella, E.T, How College Affects Students, 1991, San Francisco, CA: Jossey-Bass Publishers

ii Moriarty, Debra, Ph.D Thesis, Leadership and the College Experience. 1994, Ann Arbor, MI: UMI.

iii The mission of the University of Michigan is to serve the people of Michigan and the world through preeminence in creating, communicating, preserving and applying knowledge, art, and academic values, and in developing leaders and citizens who will challenge the present and enrich the future.

iv Learning Leadership \& Citizenship: Implications and Applications A Model for Discussion by the Campus Community, October 1997. Copies are available by calling the University of Michigan Office of Student Affairs, (734) 764-5132.

v Astin, A.W. \& Astin, H.S. (1996). A Social Change Model of Leadership Development. University of California Los Angeles: Higher Education Research Institute.

Bennis, W. (1989). On Becoming a Leader. Reading, MA: Addison Wesley Publishing Company.

Bennis, W. (1997). The Secrets of Great Groups. In Leader to Leader, no. 3. San Francisco, CA: JosseyBass.

Senge, P.M. (1990). The Fifth Discipline: The art and practive of the learning organization. N ew York, NY: Double Day.

vi Gardner, J.W. (1990). On Leadership. New York, NY: The Free Press.

vii Spencer,L.M, Competence at Work, 1993. New York, NY John Wiley \& Sons

viii Covey, Stephen. (1989). Seven Habits of Highly Effective People. New York: Simon and Schuster.

ix This material is taken from the report Curriculum 2000, Team Building through the

Curriculum,N ovember 20, 1997.

X Johnson, V., Becoming Engineers and Teaming on Design Projects, 1996.

$\mathrm{xi}$ This is part of the MLI Task Force report with modifications applicable to the College of Engineering. The expected time of instruction (i.e., freshman or sophmore year) is shown next to each skill name. 